\title{
Witnessed presence
}

\author{
Caroline Nevejan $\cdot$ Satinder P. Gill
}

Published online: 25 September 2011

(c) The Author(s) 2011. This article is published with open access at Springerlink.com

This special issue of AI and Society, Journal for Knowledge, Culture and Communication explores the notion of witnessing in the evolving technological culture. Whereas witnessing is a concept used mostly within the courtroom and has legal connotations for many, it originally refers to a process of being in the presence of each other. To be witness and to bear witness is distinct; through witnessing truth is assessed and trust established.

Human beings, in the act of being witness and bearing witness, have been mediating presence for centuries by leaving traces, telling stories, making images and music, and writing text. However, digital technology facilitates mediation of presence at scales and speeds unknown before and as a result of this mediation, the dynamics of being witness and bearing witness are changing. Personal, organization and business communication is deeply affected by new ways of connecting, sharing knowledge and doing transactions. Social structures adapt and constantly restructure processes impacted by the rapid pace of changing information and communication technologies. Foundations of social structures, including power relations, identity building, trust, liability, and justice, are being challenged. As Manuel Castells formulated already 15 years ago in his impressive trilogy on the rise of the networked society:

\section{Nevejan ( $\square)$}

Faculty Technology, Policy and Management,

Delft Technical University, Jaffalaan 5,

2628 BX Delft, The Netherlands

e-mail: C.I.M.Nevejan@tudelft.nl

\section{S. P. Gill}

Centre for Music and Science, Faculty of Music, University of Cambridge, 11 West Road, Cambridge CB3 9DP, UK

e-mail: spg12@cam.ac.uk
'Thus, people do still live in places. But because function and power in our societies are organized in the space of flows, the structural domination of its logic essentially alters the meaning and dynamic of places. Experience, being related to places, becomes abstracted from power, and meaning is increasingly separated from knowledge. The dominant tendency is toward a horizon of networked, a historical space of flows, aiming and imposing its logic over scattered, segmented places, increasingly unrelated to each other, less and less able to share cultural codes. Unless cultural and physical bridges are deliberately built between these two forms of space, we may be heading toward life in parallel universes whose times cannot meet because they are warped into different dimensions of social hyperspace'. (Castells 1996, 428). ${ }^{1}$

For the building of such bridges, a better understanding of witnessed presence is essential. When building bridges between the space of places and the space of flows, an ethical position of the witness seems unavoidable. How else can social structures that offer well-being and survival emerge? The construction of such bridges needs to include elements that allow for human presence and human consciousness to partake in a variety of modes. Physical and sensorial elements need to allow for immaterial interaction to emerge. This special issue of AI and Society aims to identify possibilities and hurdles in such a quest.

In the spring of 2010, we published the call to contribute to this special issue on Witnessed Presence for AI and Society, Journal for Knowledge, Culture and Communication. Authors in this special issue generously offer

\footnotetext{
${ }^{1}$ Castells distinguishes between the space of places and the space of flows that consists of mediated presences and endless data streams which structure the financial, economic and social structures in the global networked society (Castells 1996).
} 
perspectives on witnessed presence from a variety of disciplines. Some contributions are theoretical; others reflect applied research. Contributions focus on a deeper understanding of witnessing and address the changing human condition in which information and communication technologies play an increasing significant role.

In the first paper, Phil Turner, Philosopher at Napier University in Edinburgh, eloquently discusses an everyday ontology of witnessing, drawing on the writings of Martin Heidegger. Having been involved in the EU presence community for over 10 years, he describes how (tele-) presence has been approached from the perspective of having the sense of 'being-there'. He concludes that witnessing is one of the consequences of being-in-the-world, of being-here, and suggests that the internet and other mediated contexts may facilitate witnessing. He lays down three premises for witnessing: presence, availability and representation. Presence has intentionality through which the body is bound to the world. When witnessing, this intentionality is 'inherited'. This hints to witnessed presence as a force that creates social structures by sharing and inheriting 'intentionality'. The second premise, 'availability', is a matter of experience and embodiment is at its root. The body is the instrument that defines what it is to be available and qualifies witnessing. Thirdly, witnessing (recognizing what you see) builds on weak representations (things that only become active when an individual is engaged), while bearing witness (giving testimony) builds on strong representations (things that stand for something). When being witness or when bearing witness, the distinction between weak and strong representations allows for a better understanding of the kinds of mediated details an individual needs in specific contexts.

These processes of being and bearing witness are deeply interwoven, and even happen in the same instance, argues Frans-Willem Korsten, professor of Literature at the University of Utrecht. Korsten describes how, when being in mediated presence with its lack of other cues, words have to act. Text and language become fundamental and from software to Skype, it is the foundation of mediated presence. Words are actors. Korsten revisits the rhetoric figure of apostrophe (not to be confused with the punctuation mark), which in specific cases denotes that bearing and being witnessed happen in the same instance in the same utterance spoken/line written. To be a witness means to offer and address attention to what is being witnessed, and to bear witness, and thereby turning away from the situation at hand to offer an address of expression to a 'virtual audience'. The address of expression functions like a comment on the situation. By functioning like a comment, values are questioned and ethics are communicated. Peripheral perception is fundamental here: when words act, direct focus is not possible and words start functioning like images, hence the use of metaphors that sketch associations and hint to associations. The rhetorical figure of the apostrophe works because it is not direct. In his contribution, Korsten analyses a text by Maria Dermôut on Pattimura and an exposition by Kara Walker on the New Orleans flooding. He concludes that in modern media this dual modality is lost as is ethical awareness.

However, argues Sjoukje van der Meulen, art historian and media theorist at the University of Illinois at Chicago, ethical awareness can exist when media is orchestrated in such a way that it deconstructs, contradicts and amends itself in confrontation with the witness. Van der Meulen analyses and contextualizes the work of media-artist Pierre Huyghe, who with great sophistication, consistently seduces and confuses people in being witness to his work. Huyghe's work lends itself to presence theories within the field of media studies as well as art theory and criticism. Van der Meulen applies Nevejan's presence theory and finds that Huyghe plays out the tensions between natural, mediated and witnessed presence. Van Der Meulen uses Samuel Webers's notion of mediaura to explain the way in which the power of fiction grants an auratic effect to characters that appear in Pierre Huyghe's work. Van der Meulen concludes that next to natural, mediated and witnessed presence, fictional presence is fundamental to being able to understand why specific media configurations create meaning in the field of art?

Stephanie Bezanquen, a French philosopher focusing on cultural representations of genocide and mass murder, offers a perspective on witnessed presence in dramatic and dramatized participatory projects of theatre and film that aim to unveil the truth, to help people cope with the trauma of the Pol Pot regime in Cambodia. Bezanquen presents an analysis of a film and theatre play produced by westerners and a film and yearly performance of a historical walk initiated by Cambodians. Western organizers experienced difficulties in applying the Cambodian culturally rooted hybrid model of transitional justice to their work. Only the work by the Cambodian filmmaker offered the honesty to confront the westerners with the amnesia about the part their western leaders played in Cambodia's epic tragedy. Nevertheless, the western production contributed to 'recognition beyond recognition' in which cultural differences in coming to terms with historical trauma are expressed and recorded. Bezanquen argues that in dramatic and mediated contexts, specific social, cultural and historical contexts of witnessing remain distinct for understanding experience and meaning that emerge.

Introducing the concept of the 'healing witness', Sheryl Brahnam explores the vital importance of witnessing in the mediation of self-narratives (and the self). Noting how trauma challenges self-narratives, Brahnam provides a comprehensive exploration of what it means to bear 
witness to another's suffering so healing can take place. According to Brahnam, the healing witness is a willing and capable listener, someone who makes room for a time of remembrance so that meaning and self-narratives can emerge from the undigested, raw experiences of suffering. Using contemporary trauma theory originating from the work of Pierre Janet and Julia Kristeva's concept of the symbolic and the semiotic, which roughly correspond to the conscious and unconscious aspects of signification, Brahnam shows not only what it means to bear witness to suffering but also how opportunities for witnessing are disappearing, in part due to our uses of technology. Whereas reading and writing provide practices that enlarge our capacities to empathize and to imagine, modern forms of mediation are constricting those capacities and disordering memory and time in ways that resemble trauma. Unless technology opens us more to the imaginary, Brahnam believes 'we risk losing the capacity to bear witness to one another and to create narratives and connections that are meaningful'.

Connecting the work of these five previously mentioned authors, it seems that the imaginary and fictional presence is fundamental to witnessing. Even more so, since we have so much mediated communication around. Whether the witness will be able to have an ethical position depends on media configurations and their potential to include the imaginary and fictional presence. The following three contributions explore how presence configurations can be designed, what elements human beings need to perform their presence and enter into the in-between. Architect Charlie Gullstrom, psychologist Satinder Gill and social scientist Caroline Nevejan with computer scientist Frances Brazier present current research into the factors that contribute to building witnessed presence.

A presence-in-person paradigm prevails in our society, founded on the expectations of trust and knowledge-sharing between individuals, argues architect Charlie Gullstrom. Given that mediated spaces currently provide viable alternatives for meetings and interactions, Gullstrom takes us from presence design through to architectural practice. For centuries, human visual history has created virtual presences through the orchestration of visual space. Architecture affects how people tune their presence, and the design of space is a significant factor when building mediated presence. Gullstrom integrates media technology with architecture, introducing the concept of 'design frictions' to better understand how mediated presence can be orchestrated for witnessing to take place. In her practice as designer of mediated environments, three elements are crucial: mediated gaze, spatial montage and shared mediated space. In her contribution to this special issue, Gullstrom illustrates and discusses a variety of mediated presence designs.
How we move in time together is fundamental to witnessing. Rhythm and entrainment of the movements of our bodies and voices shapes how witnessing emerges, according to psychologist Satinder Gill. In the process of physical social presence, people tune their rhythms in breathing, movement, vocal sounds and gaze. Such tuning facilitates mutual synchronization that is needed to both bear and be witness at the same time, i.e., for witnessed presence. Mutual synchrony, or entrainment, is about how we co-adapt to each other's rhythms. In mediated presence, when there is simply a piece of glass between two people, Gill finds that such tuning is inhibited. However, even though mediated environments allow for less subtle tuning, when committed to communicate, human beings find ways to tune their presence.

How people manage to tune their presence in on and offline merging realities and establish trust, was the subject of an exploratory study by Caroline Nevejan in which 20 experts engaged in in-depth interviews with her? System participation in human communities of practice challenges the notion of witnessing and, therefore, the ability to build trust. Nevertheless, through trial and error, people in a variety of practices have found ways to establish presence and develop trust in merging realities. Together with Frances Brazier, Nevejan identifies significant factors in the four dimensions of the YUTPA framework: time, place, action and relation. Nevejan and Brazier conclude that systems output deeply affects the mental maps that human beings make of each other, the world around them and their own self. By designing granular interaction in four dimensions, reciprocity in witnessing obtains significance, and the basis for establishing trust in a variety of presences emerges whilst human agency acquires potential.

The Open Forum section of this special issue offers an analysis of three case studies from a witnessed presence perspective. John Mendy finds that actor presence is fundamental to the witnessing that takes place in reorganization processes in business organizations. Shelly Tara and Vigneswara Ilavarasan analyse the organization and use of cabs by unmarried young women call centre agents who have to commute at night in New Delhi, India. They find that the cabs and the presence of a third person in the cabs are perceived as means of producing respectability for the young women by their parents. But, introducing a third person as a witness in the cab does not create the intended trustworthiness because third persons, like the driver, are males as well. Last Maurice Berix, being a designer and civil servant of the regional government in the Netherlands, offers a visual essay in which he analyses how the orchestration of government communication may include citizen's participation by a deliberate design of presence and trust. 
This special issue shows that new bridges between the space of places and the space of flows are being constructed. However, when such bridges are built, more research is needed for ontology of presence that will include the above-identified complex dynamics of the inbetween space that constitutes witnessing. The presented studies herein clearly indicate that intention, availability, embodiment, representation, culture, imagination and fictional presence need to be incorporated in the building of these bridges. Only when being and bearing witness to each other is fully facilitated, will social structures of the future offer an environment in which human beings can survive and be well.

Further research into witnessed presence can be accessed at http://www.beig-here.net. It was a pleasure to work on this special issue thanks the board of AI and Society and its publisher Springer. We are specifically grateful to the reviewers for their time, attention and valuable comments. Most of all we appreciate the effort that each of the authors has given in offering us their best knowledge and insight.

Open Access This article is distributed under the terms of the Creative Commons Attribution Noncommercial License which permits any noncommercial use, distribution, and reproduction in any medium, provided the original author(s) and source are credited.

\section{Reference}

Castells M (1996) The rise of the networked society. Blackwell Publishing, Oxford 